To protect the rights of the author(s) and publisher we inform you that this PDF is an uncorrected proof for internal business use only by the author(s), editor(s), reviewer(s), Elsevier and typesetter SPi. It is not allowed to publish this proof online or in print. This proof copy is the copyright property of the publisher and is confidential until formal publication.

B978-0-12-391862-8.00015-6, 00015

C0075

\title{
G Protein-Coupled Receptor Heterodimerization in the Brain
}

\author{
Dasiel O. Borroto-Escuela*, Wilber Romero-Fernandez*, \\ Pere Garriga ${ }^{\dagger}$, Francisco Ciruela ${ }^{\ddagger}$, Manuel Narvaez ${ }^{\S}$ \\ Alexander O. Tarakanov", Miklós Palkovits", Luigi F. Agnati", \\ Kjell Fuxe ${ }^{*, 1}$ \\ *Department of Neuroscience, Karolinska Institutet, Stockholm, Sweden \\ ${ }^{\dagger}$ Departament d'Engieneria Química, Universitat Politècnica de Catalunya, Barcelona, Spain \\ ${ }^{\ddagger}$ Unitat de Farmacologia, Departament Patologia i Terapèutica Experimental, Universitat \\ de Barcelona, Barcelona, Spain \\ ${ }^{\S}$ Department of Physiology, School of Medicine, University of Málaga, Málaga, Spain \\ 'Russian Academy of Sciences, St. Petersburg Institute for Informatics and Automation, \\ Saint Petersburg, Russia \\ I'Magyar Tudományos Akadémia, Semmelweis Egyetem, Neuromorfológiai és Neuroendokrin \\ Kutatócsoport, Budapest, Hungary \\ \#IRCCS Lido, Venice, Italy \\ ${ }^{1}$ Corresponding author: e-mail address: Kjell.Fuxe@ki.se
}

\section{Contents}

1. Introduction

2. In Situ PLA for Demonstrating Receptor Heteromers and Their Receptor-Receptor Interactions in Brain Tissue

3. Brain Tissue Preparation

4. Proximity Probes: Conjugation of Oligonucleotides to Antibodies

5. PLA Reactions, Reagents, and Solutions

6. Quantitative PLA Image Analysis

7. Advantages and Disadvantages of the PLA Method

8. Application

\section{Abstract}

G protein-coupled receptors (GPCRs) play critical roles in cellular processes and signaling and have been shown to form heteromers with diverge biochemical and/or pharmacological activities that are different from those of the corresponding monomers or homomers. However, despite extensive experimental results supporting the formation of GPCR heteromers in heterologous systems, the existence of such receptor heterocomplexes in the brain remains largely unknown, mostly because of the lack of appropriate methodology. Herein, we describe the in situ proximity ligation assay procedure underlining its high selectivity and sensitivity to image GPCR heteromers with confocal 
To protect the rights of the author(s) and publisher we inform you that this PDF is an uncorrected proof for internal business use only by the author(s), editor(s), reviewer(s), Elsevier and typesetter SPi. It is not allowed to publish this proof online or in print. This proof copy is the copyright property of the publisher and is confidential until formal publication.

B978-0-12-391862-8.00015-6, 00015

microscopy in brain sections. We describe here how the assay is performed and discuss advantages and disadvantages of this method compared with other available techniques.

s0005

p0005 of the corresponding monomers or homomers. The idea of the existence of direct interactions between two different GPCRs at the level of the plasma membrane has its origin in 1980/1981 on the basis of the discovery that peptides like cholecystokinin-8 (CCK-8) and substance P could modulate the density, and especially the affinity, of distinct monoamine receptors in membrane preparations from the CNS with in vivo functional correlates (Agnati, Fuxe, Zini, Lenzi, \& Hokfelt, 1980; Fuxe et al., 1981). These initial findings were in line with the previous discovery of negative cooperativity between $\beta$ adrenergic receptors in 1974/1975 by Lefkowitz and colleagues, indicating the possible existence of homodimers of $\beta$ adrenergic receptors leading to site-site interactions in recognition (Limbird, Meyts, \& Lefkowitz, 1975).

p0010 Nevertheless, despite extensive experimental results supporting the formation of GPCR heteromers in heterologous systems, the existence of such receptor heterocomplexes in their native environment remains largely unknown, mostly because of the lack of appropriate methodology. For instance, until recent years, the methods that have been developed to study receptor-receptor interactions in heteromers require that genetic constructs be expressed in the cells to enable detection of the receptor interactions, thus excluding the use of tissue samples (Borroto-Escuela, Garcia-Negredo, Garriga, Fuxe, \& Ciruela, 2010; Ferre et al., 2009; Fuxe et al., 2012).

p0015 In order to demonstrate in native tissue the existence of GPCR heteromers, especially in a manner that can be generally applicable to different receptor pairs, a well-characterized in situ proximity ligation assay (in situ PLA) has been adapted to confirm the existence of GPCR heteromers in brain slices ex vivo.

p0020 In situ PLA is based on a pair of antibodies that can bind to target proteins and to which oligonucleotides have been attached. When the so-called proximity probes recognize a target, for example, if the two target receptors interact, the attached oligonucleotides are brought into a sufficiently close 
To protect the rights of the author(s) and publisher we inform you that this PDF is an uncorrected proof for internal business use only by the author(s), editor(s), reviewer(s), Elsevier and typesetter SPi. It is not allowed to publish this proof online or in print. This proof copy is the copyright property of the publisher and is confidential until formal publication.

B978-0-12-391862-8.00015-6, 00015

spatial proximity to allow them to join followed by ligation of the two linear oligonucleotides into a circular DNA molecule. This newly formed DNA circle strand can serve as a template for rolling circle amplification (RCA), resulting in a long single-stranded rolling circle product (RCP) attached to one of the proximity probes. As the RCP is linked to the proximity probe, it is attached at the site where the proximity probe bound, which means that it can be used to reveal the location of the receptor complex (Soderberg et al., 2006, 2007). The RCPs can then be detected and quantified by hybridizing fluorescent oligonucleotides to the repeated sequences of the RCPs, rendering them visible by fluorescence microscopy (Fig. 15.1).

p0025 Herein, we describe the in situ PLA procedure as a high selectivity and sensitivity assay to image GPCR heteromers in brain sections by confocal microscopy. We describe how the assay is performed and discuss advantages and disadvantages of this method compared with other available techniques.

\section{In Situ PLA FOR DEMONSTRATING RECEPTOR HETEROMERS AND THEIR RECEPTOR-RECEPTOR INTERACTIONS IN BRAIN TISSUE}

In situ PLA has previously been performed to confirm the existence of striatal $\mathrm{A}_{2 \mathrm{~A}} \mathrm{R}-\mathrm{D}_{2} \mathrm{R}$ heteromers (Trifilieff et al., 2011). The PLA technique involved the use of two primary antibodies of different species directed to either $\mathrm{D}_{2} \mathrm{R}$ or to $\mathrm{A}_{2 \mathrm{~A}} \mathrm{R}$ (Fig. 15.2). We recommend to use in situ PLA also to indicate the ratio between heteromers versus total number of the two participating receptor populations, using in addition to Western blots, receptor autoradiography, and biochemical binding methods, the two latter methods showing the densities and affinities of the two functional receptor populations. This will also help to normalize the heteromer values for comparison between groups in addition to evaluating the potential changes in the total number of the two receptor populations. The person doing the PLA measurements should be blind to the code of the experimental groups studied.

\section{BRAIN TISSUE PREPARATION}

As for all antibody-based staining methods, the samples should be sufficiently pretreated to fit the primary antibodies with respect to fixation, permeabilization, and antigen retrieval of the tissue to be investigated. As the protocols provided in this section are general, it is highly suggested to apply the same protocol that has been working previously for your receptor 
To protect the rights of the author(s) and publisher we inform you that this PDF is an uncorrected proof for internal business use only by the author(s), editor(s), reviewer(s), Elsevier and typesetter SPi. It is not allowed to publish this proof online or in print. This proof copy is the copyright property of the publisher and is confidential until formal publication.

B978-0-12-391862-8.00015-6, 00015

A

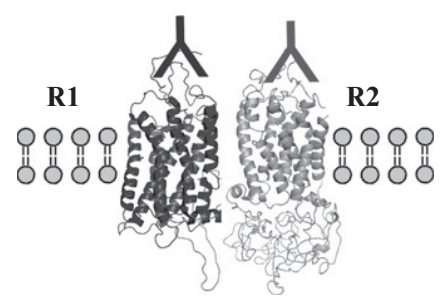

$\mathrm{C}$

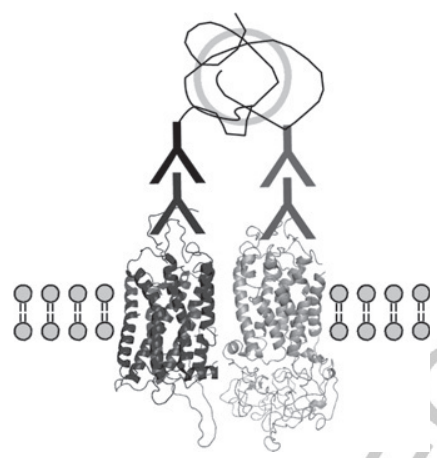

B

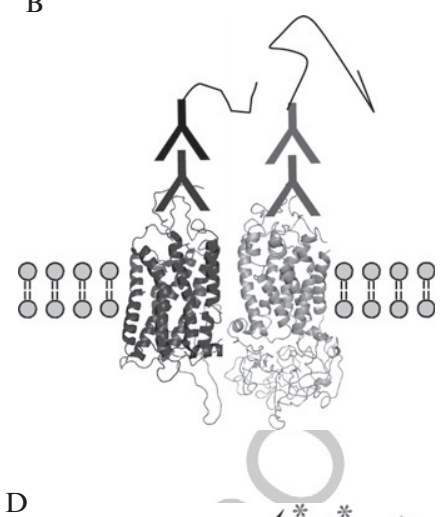

$\mathrm{D}$

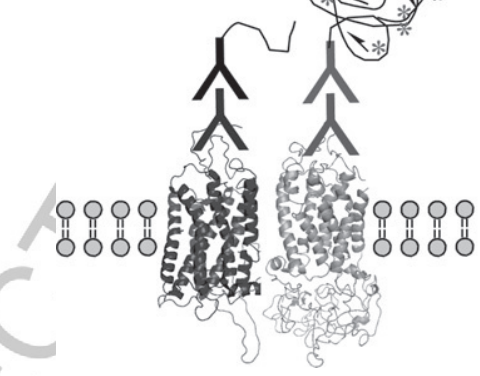

f0005 Figure 15.1 Schematic presentation of in situ PLA for detection of GPCR heteromers in the brain. (A) Two primary antibodies from different species are used to detect each receptor heteromer protomers (R1 and R2). (B) Each species-specific secondary antibody with attached oligonucleotide DNA probes (proximity probes) is targeted to the corresponding primary antibody, and when they are in a close proximity (the distance between the two secondary antibodies is a maximum of $10-20 \mathrm{~nm}$ as calculated from a DNA arm of 25-35 bp), the proximity probes serves as a template for the hybridization of circularization oligonucleotides, which are then joined by ligation into a circular DNA molecule (C). The circular DNA molecule is then amplified by rolling circle amplification (RCA) primed by one of the proximity probes and using a polymerase to yield a long concatemeric copy of the rolling circle that remains covalently attached to the proximity probe (D). The RCA product can subsequently be identified by hybridization of fluorophore-labeled complementary oligonucleotide probes added to highlight the product. (For color version of this figure, the reader is referred to the online version of this chapter.)

pairs in immunohistochemistry. Thus, similar conditions as employed for immunohistochemistry can be used for in situ PLA reactions.

p0040 For in situ PLA, the common options are fixed (paraffin-embedded or cryostat sections and vibratome sections) or unfixed cryostat (frozen) sections. The choice of section is determined by a number of conditions, 
To protect the rights of the author(s) and publisher we inform you that this PDF is an uncorrected proof for internal business use only by the author(s), editor(s), reviewer(s), Elsevier and typesetter SPi. It is not allowed to publish this proof online or in print. This proof copy is the copyright property of the publisher and is confidential until formal publication.

B978-0-12-391862-8.00015-6, 00015
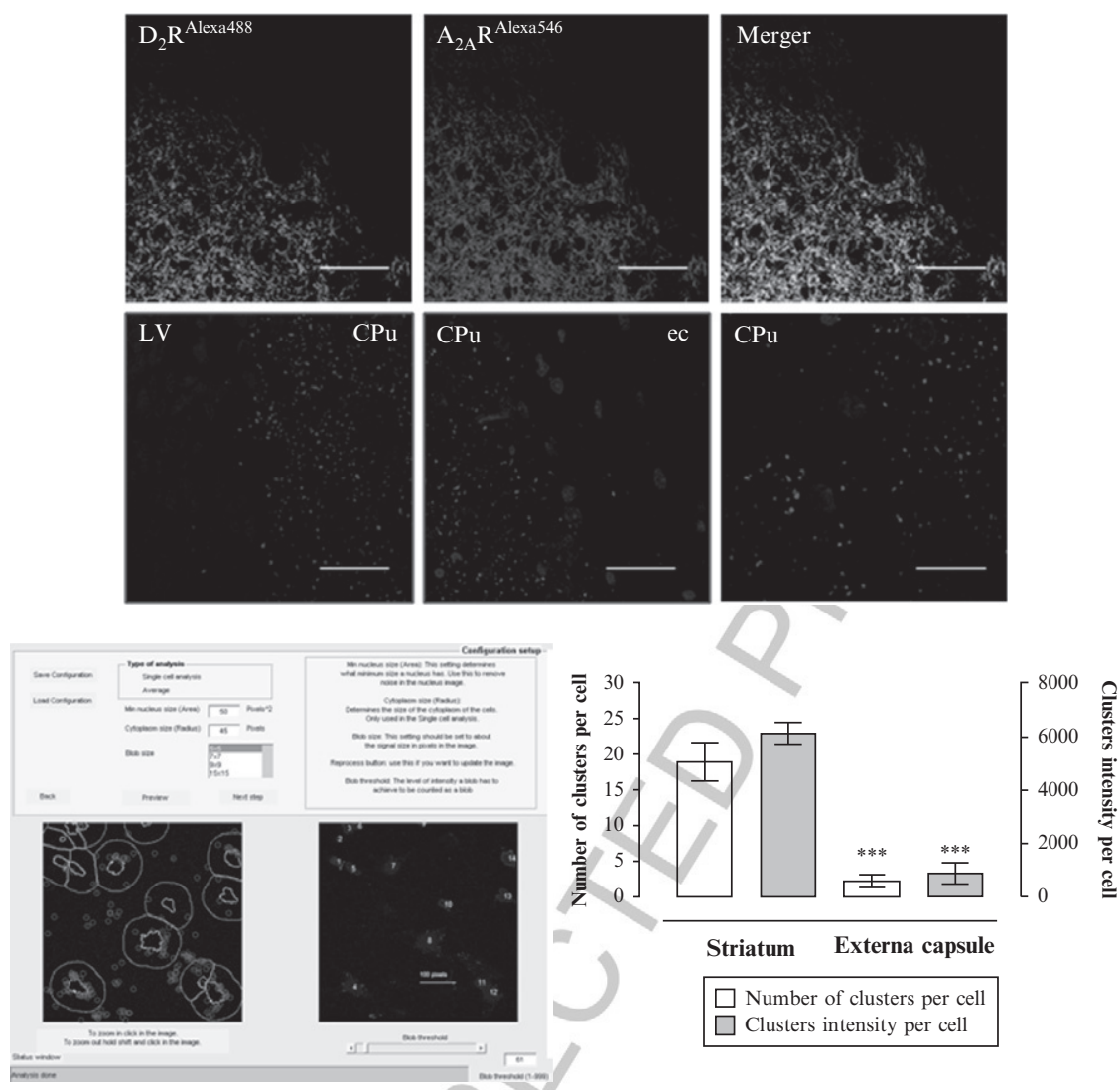

f0010 Figure 15.2 Upper-upper panel: Specific $D_{2} R$ (green) and $A_{2 A} R$ (red) immunoreactivities and colocalization (yellow) in striatal sections. $D_{2} R$ immunoreactivity was high in the striatum of rat surrounded by the external capsule (ec) using fluorescence immunohistochemistry (left). $A_{2 A} R$ immunoreactivity (middle) showed a high level of colocalization with $D_{2} R$ (right) in the striatum of wild-type rat. Scale bars, $75 \mu \mathrm{m}$. Upper-down panel: PLA-positive $A_{2 A} R-D_{2} R$ heteromers in striatal sections adjacent to the sections with immunoreactivity $A_{2 A} R-D_{2} R$ heteromers were visualized as red clusters (blobs, dots) within the striatum which were almost absent within the lateral ventricle (LV, left) and the external capsule (ec, middle panel). Higher magnification image revealed a large number of PLA-positive red clusters within the caudate putamen ( $\mathrm{CPu}$, right). Each cluster represents a high concentration of fluorescence from the single-molecule amplification resulting from several hundred-fold replication of the DNA circle formed as a result of the probe proximity; the cluster/dot number can be quantified independently of the intensity. Nuclei are shown in blue (DAPI). Scale bars, $50 \mu \mathrm{m}$ for left and middle panels; $20 \mu \mathrm{m}$ for the right panels. Lower-left panel: Screendump from the corresponding BlobFinder analysis. The left pictures show how the software has identified the PLA signals, the nuclear limit, and the approximate limit of the cytoplasm based on a user-defined radius. The right picture shows the raw image based on 14 $Z$-planes with the nuclei enumerated. Lower-right panel: PLA-positive red clusters in striatum were quantified per cell using BlobFinder and the results are presented. 
To protect the rights of the author(s) and publisher we inform you that this PDF is an uncorrected proof for internal business use only by the author(s), editor(s), reviewer(s), Elsevier and typesetter SPi. It is not allowed to publish this proof online or in print. This proof copy is the copyright property of the publisher and is confidential until formal publication.

B978-0-12-391862-8.00015-6, 00015

including the time and skill of the investigator. However, careful consideration of the fixation protocol is especially necessary to ensure the optimal preservation of the morphology of the specimen and target antigen (receptors). Incorrect specimen preparation can block or impede antigen labeling in the tissue. Unfortunately, the methods that are best for the preservation of tissue structure do so by modifying proteins, thereby reducing the efficiency of antigen detection. In cases of failure, it is important to try with multiple different conditions before you give up the in situ PLA.

00005 1. Because of the ease of use, fixed frozen free-floating sections are often employed in most of the in situ PLA experiments. First, animals are anesthetized by an intraperitoneal injection of, for example, pentobarbital $(60 \mathrm{mg} / \mathrm{ml},[0.1 \mathrm{ml} / 100 \mathrm{~g}])$ and perfused intracardially with $30-50 \mathrm{ml}$ of ice-cold 4\% paraformaldehyde (PFA) in $0.1 \mathrm{M}$ phosphate-buffered saline (PBS), $\mathrm{pH} \mathrm{7.4,} \mathrm{solution.} \mathrm{After} \mathrm{perfusion,} \mathrm{brains} \mathrm{are} \mathrm{collected} \mathrm{and}$ transferred into well-labeled glass vials filled with 4\% PFA fixative solution for $6 \mathrm{~h}$. Then, the brain pieces are placed in sucrose 20\% in PBS and incubated for $24 \mathrm{~h}$ until sections $(10-30 \mu \mathrm{m}$ thick) are generated and serially collected using a cryostat. Alternatively to the use of fixed freefloating sections, we can use tissue fixed frozen sections attached to microscopy slides. Mounted sections on slides must be kept at $-20^{\circ} \mathrm{C}$ until use. Encircle the tissue section on the glass slide by creating a hydrophobic barrier using a grease pen or a silicon mask and proceed as follows.

00010 2. Wash the fixed free-floating sections four times with PBS, then incubate with the blocking solution (10\% fetal bovine serum [FBS] and $0.5 \%$ Triton X-100 or Tween-20 in Tris buffer saline [TBS], $\mathrm{pH} 7.4$ ) for $2 \mathrm{~h}$ at room temperature or $1 \mathrm{~h}$ at $37^{\circ} \mathrm{C}$ and then follow the Protocol step 5.

p0055 To reduce the likelihood of unspecific binding of the antibodies to the tissue, the tissue needs to be blocked by a blocking agent, such as bovine serum albumin (BSA; by adding $1 \mu \mathrm{BSA}(10 \mathrm{mg} / \mathrm{ml})$ and $1 \mu \mathrm{l}$ sonicated salmon sperm DNA $(0.1 \mathrm{mg} / \mathrm{ml})$ to $38 \mu \mathrm{l}$ of $0.5 \%$ Triton $\mathrm{X}-100$ or Tween-20 in TBS, pH 7.4; Leuchowius, Weibrecht, \& Soderberg, 2011) or animal serum like $10 \%$ FBS (if animal serum is used, make sure that it is sterile filtered, as unfiltered serum may increase the amount of background signals). Use the blocking agent best suited for the antibodies used. Each time must be

Quantification of $A_{2 A} R-D_{2} R$ heteromers demonstrates highly significant differences in PLA clusters per cell between caudate putamen and external capsule ( ${ }^{* *} P<0.001$ by Student's $t$-test). (See Color Insert.) 
To protect the rights of the author(s) and publisher we inform you that this PDF is an uncorrected proof for internal business use only by the author(s), editor(s), reviewer(s), Elsevier and typesetter SPi. It is not allowed to publish this proof online or in print. This proof copy is the copyright property of the publisher and is confidential until formal publication.

B978-0-12-391862-8.00015-6, 00015

checked that the reaction should never become dry as this will cause high background.

s0020

\section{PROXIMITY PROBES: CONJUGATION OF OLIGONUCLEOTIDES TO ANTIBODIES}

Proximity probes are created through the attachment of oligonucleotides to antibodies. The oligonucleotide component of the proximity probes can be covalently coupled to an antigen-binding component or attached to secondary antibodies specific for antibodies raised in different species. This approach avoids the need to conjugate the oligonucleotide components to each primary antibody pair.

p0065 Several different types of chemistry can be used for the conjugation of oligonucleotides to antibodies. Mainly three methods have been used extensively in recent years: the maleimide/NHS-esther chemistry (SMCC; Soderberg et al., 2006), the succinimidyl 4-hydrazinonicotinate acetone hydrazone (SANH; Leuchowius et al., 2011), or the commercially available Antibody-Oligonucleotide All-in-One Conjugation Kit from Solulink company (http://www.solulink.com/), based on two complementary heterobifunctional linkers (Sulfo-S-4FB (formylbenzamide) and S-HyNic (hydrazino-nicotinamide)). Because the act of conjugation can severely affect the ability of some antibodies to bind antigen, it may be necessary to analyze different antibodies, conjugation chemistries, and reaction conditions to obtain suitable proximity probes.

p0070 Another possibility, not less useful, is to buy directly proximity probes from specialized companies on antibody-oligonucleotide conjugation, for example, Duolink (Uppsala, Sweden; http://www.olink.com/).

\section{PLA REACTIONS, REAGENTS, AND SOLUTIONS}

00015 1. If primary antibodies directly labeled with oligonucleotides or primary antibodies are used in combination with secondary proximity probes (see Protocol step 4), the conditions for incubation with the primary antibodies should be chosen according to the manufacturer's recommendations or will have to be identified by the users. For instance, incubate the tissue with the primary antibodies diluted into a suitable concentration in the wash buffer $(0.5 \%$ Triton X-100 or Tween-20 in TBS, $\mathrm{pH} 7.4)$ at $1-2 \mathrm{~h}$ at $37^{\circ} \mathrm{C}$ or $+4{ }^{\circ} \mathrm{C}$ overnight. 
To protect the rights of the author(s) and publisher we inform you that this PDF is an uncorrected proof for internal business use only by the author(s), editor(s), reviewer(s), Elsevier and typesetter SPi. It is not allowed to publish this proof online or in print. This proof copy is the copyright property of the publisher and is confidential until formal publication.

B978-0-12-391862-8.00015-6, 00015

00020

00025

00030

00035

00040

2. After incubation of the primary antibodies at conditions specified above or determined by the user, excess antibody should be removed. Wash the slides four times, 5 min each time, with wash buffer.

3. In the mean time, if primary antibodies are used in combination with secondary proximity probes, dilute the proximity probes to a suitable concentration in the wash buffer. It is important to use the same buffer as those for the primary antibody to avoid background staining. Apply the proximity probe mixture to the sample and incubate for $1 \mathrm{~h}$ at $37^{\circ} \mathrm{C}$ in a humidity chamber. Do not allow the samples to dry, as this will cause also artifacts. To remove unbound proximity probes, wash the slides four times, 5 min each time, with wash buffer.

4. Prepare the hybridization-ligation solution. To ensure optimal conditions for the enzymatic reactions, the sections should be soaked for $1 \mathrm{~min}$ in $1 \times$ ligation buffer $(10 \mathrm{~m} M$ Tris-acetate, $10 \mathrm{mM}$ magnesium acetate, $50 \mathrm{mM}$ potassium acetate, $\mathrm{pH}$ 7.5; Soderberg et al., 2008), prior to addition of the hybridization-ligation solution (final concentration: BSA $(250 \mu \mathrm{g} / \mathrm{ml}), 1 \times \mathrm{T} 4$ DNA ligase buffer, Tween-20 (0.05\%), $\mathrm{NaCl} 250 \mathrm{mM}$, ATP $1 \mathrm{mM}$, and the circularization or connector oligonucleotides 125-250 $\mathrm{nM}$ ). Circularization or connector oligonucleotides can be designed and synthesized as described previously (Soderberg et al., 2008). Remove the soaking solution (ligation buffer) and add T4 DNA ligase at a final concentration of $0.05 \mathrm{U} / \mu 1$ to the hybridization-ligation solution. Vortex briefly to mix the ligase with the solution. Apply the mixture immediately to the sections and slides in a humidity chamber for $30 \mathrm{~min}$ at $37^{\circ} \mathrm{C}$.

5. Wash the sections three times with wash buffer in a washing jar for 5 min to remove excess connector oligonucleotides.

6. Prepare the RCA mixture. Soak the sections in $1 \times$ RCA buffer (50 mM Tris- $\mathrm{HCl}, 10 \mathrm{mM} \mathrm{MgCl} 2,10 \mathrm{mM}\left(\mathrm{NH}_{4}\right)_{2} \mathrm{SO}_{4}, \mathrm{pH} 7.5$ adjusted with $\mathrm{HCl}$ ) for $1 \mathrm{~min}$. Remove the soaking solution and add the RCA solution (final concentration: phi-29 polymerase $0.125-0.200 \mathrm{U} / \mu \mathrm{l}, \mathrm{BSA}(250 \mu \mathrm{g} / \mathrm{ml}), 1 \times \mathrm{RCA}$ buffer, Tween-20 $(0.05 \%)$, and dNTP $(250 \mu M$ for each)). Vortex briefly the RCA solution and incubate in a humidity chamber for $100 \mathrm{~min}$ at $37^{\circ} \mathrm{C}$.

7. Wash the sections three times with wash buffer in a washing jar for $5 \mathrm{~min}$. Prepare the detection solution (final concentration: BSA $(250 \mu \mathrm{g} / \mathrm{ml}), 2 \times$ sodium citrate, sodium chloride buffer, and the fluorescence detection (e.g., Texas Red or Alexa 555)-oligonucleotide strand $(6.25 \mathrm{nM})$ ), see Soderberg et al., 2008) and incubate the sections in a humidity chamber for $30 \mathrm{~min}$ at $37^{\circ} \mathrm{C}$. Keep the detection 
To protect the rights of the author(s) and publisher we inform you that this PDF is an uncorrected proof for internal business use only by the author(s), editor(s), reviewer(s), Elsevier and typesetter SPi. It is not allowed to publish this proof online or in print. This proof copy is the copyright property of the publisher and is confidential until formal publication.

B978-0-12-391862-8.00015-6, 00015

solution in the dark to prevent fluorophore bleaching. From now on, all reactions and wash steps should be performed in the dark.

00050

00055

00060

s0030

00065

1. Visualize the sections with fluorescence microscopy equipped with excitation/emission filters compatible with the fluorophores used. The in situ PLA signals have a very characteristic appearance that is easily recognized once you know what to look for. The PLA detection reaction products are seen as bright fluorescent puncta of submicrometer size (see Fig. 15.2). By moving the focus up and down in your sample tissue, you should note appearance and disappearance of PLA signals. Up to a certain density of PLA signals, they appear as discrete dots (puncta, blobs) that can be easily enumerated using image analysis software.

000702 . Analyze the captured images by image techniques to quantify the number of dots (Fig. 15.2, lower panel). Many commercial image analysis software packages can also be used in addition to free software packages, such as BlobFinder (Allalou \& Wahlby, 2009) or Cellprofiler (Carpenter et al., 2006). The BlobFinder is a free software tool developed by the Centre for Image Analysis-Uppsala University for such objectives (the freeware is available for download from http://www.cb.uu.se/ amin/BlobFinder/; Fig. 15.2, lower panel). At higher densities per number of nuclei, the dots start to coalesce, thus making it more difficult to resolve and enumerate individual signals. It is important to use the same settings for image acquisition for all images in a series.

s0035

\section{ADVANTAGES AND DISADVANTAGES OF THE PLA} METHOD

p0145

Comparison with other methods to study receptor-receptor interactions in heteromers, such as FRET, BRET, and bimolecular fluorescence complementation: In situ PLA can offer advantages by permitting analyses of interactions 
To protect the rights of the author(s) and publisher we inform you that this PDF is an uncorrected proof for internal business use only by the author(s), editor(s), reviewer(s), Elsevier and typesetter SPi. It is not allowed to publish this proof online or in print. This proof copy is the copyright property of the publisher and is confidential until formal publication.

B978-0-12-391862-8.00015-6, 00015

among any receptors for which suitable antibodies are available without using genetic constructs. Such constructs can perturb cellular function and cannot always be used, for example, in cells and tissues from subjects. In situ PLA can be performed in all samples of cells and tissues, and the method is highly suited to investigate human specimens collected from biobanks, in order to investigate patterns of changes in heteromers that could provide insights on the role of basic heteromer mechanisms or have a diagnostic value (Nilsson et al., 2010). The method has also proven useful to monitor the effects of different compounds like agonists and antagonists or their combined treatment on the receptor heteromers in cells and tissue (Borroto-Escuela et al., 2011). The information is obtained at a resolution of individual cells or even of subcellular compartments, providing profound insights into cellular heterogeneity in tissues. The method also provides an enhanced sensitivity and selectivity compared with many other methods as powerful RCA and dual target recognition are used (Clausson et al., 2011).

p0150 As with any method there are limitations, for instance, in situ PLA cannot be used with live cells, as it requires cell fixation and, in some cases, permeabilized cells. When studying receptor-receptor interactions, it is important to remember that the method, like many other methods for studying protein-protein interactions, can show that two proteins are in close proximity and likely directly interact. Proteins can also interact indirectly through an adapter protein. The maximal distance between two epitopes to give rise to a signal with in situ PLA is $10-30 \mathrm{~nm}$ with direct-conjugated proximity probes, and slightly longer when secondary proximity probes are used. By changing the length of the oligonucleotides, the maximal distance limits can be reduced or increased.

p0155 Other critical parameters for achieving good results is the use of excellent antibodies. The antibodies must also be used under optimal conditions taking into consideration parameters such as antibody concentration, epitopes targeted by the antibodies, fixation, antigen retrieval, blocking conditions, etc. A range of controls both positive and negative ones should be used to guarantee the specificity of the PLA signal. Positive controls can include cells where the protein is known to be expressed, such as in certain cells or tissues or in cells transfected to express the protein. Negative controls include cells or tissues that do not express the protein or where the protein has been knocked out or downregulated by, for example, siRNA. 
To protect the rights of the author(s) and publisher we inform you that this PDF is an uncorrected proof for internal business use only by the author(s), editor(s), reviewer(s), Elsevier and typesetter SPi. It is not allowed to publish this proof online or in print. This proof copy is the copyright property of the publisher and is confidential until formal publication.

B978-0-12-391862-8.00015-6, 00015

\section{APPLICATION}

In situ PLA has been used to study proteins and protein-protein interactions in a range of applications (Leuchowius et al., 2010; Nilsson et al., 2010). In 2011, the method was employed to study GPCR s heteromers, mainly adenosine $A_{2 A}$ and dopamine $D_{2}$ receptor heteromers in striatal sections (Trifilieff et al., 2011) and dopamine $\mathrm{D}_{2} \mathrm{R}$ and $\mathrm{D}_{4} \mathrm{R}$ in transiently transfected HEK293T cells (Borroto-Escuela et al., 2011). In addition, the methods were employed to demonstrate for the first time the existence of FGFR1 and 5-HT1A receptor heterocomplexes in the rat hippocampus and dorsal and median raphe in the midbrain (Fig. 15.3A; Borroto-Escuela et al., 2012).

p0165 In the analysis using in situ PLA, it is also important to determine the ratio between heteromers versus total number of the two participating receptor populations, using in addition to Western blots, receptor autoradiography, and biochemical binding methods, the two latter methods showing the densities and affinities of the two functional receptor populations. The relationship between these parameters will help to normalize the heteromer values for comparison between groups in addition to evaluating the potential

A
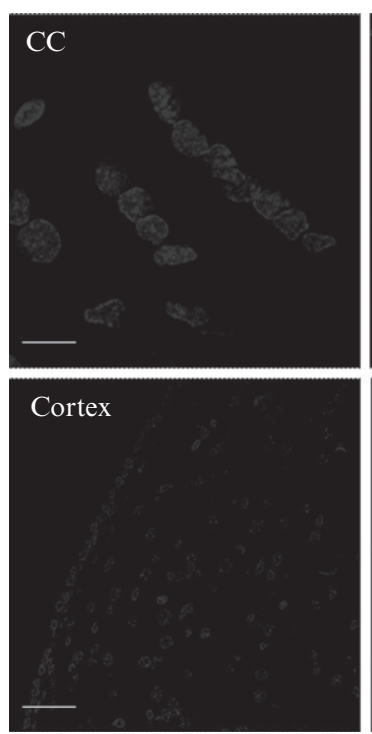
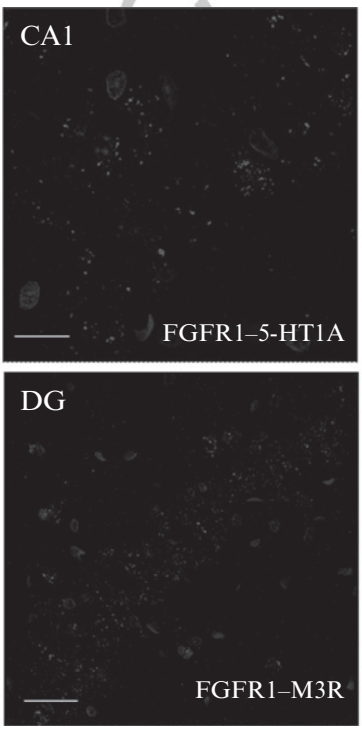
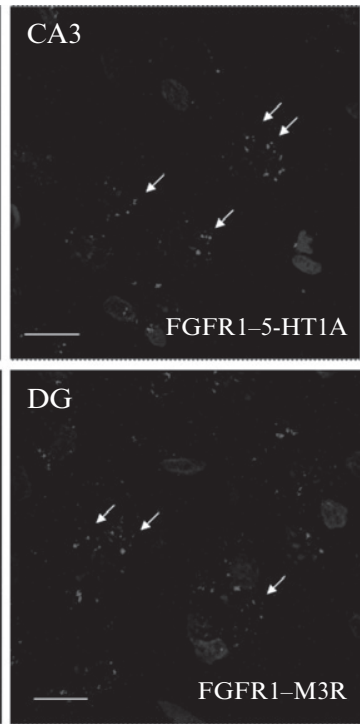

(Continued) 
To protect the rights of the author(s) and publisher we inform you that this PDF is an uncorrected proof for internal business use only by the author(s), editor(s), reviewer(s), Elsevier and typesetter SPi. It is not allowed to publish this proof online or in print. This proof copy is the copyright property of the publisher and is confidential until formal publication.

B978-0-12-391862-8.00015-6, 00015

B
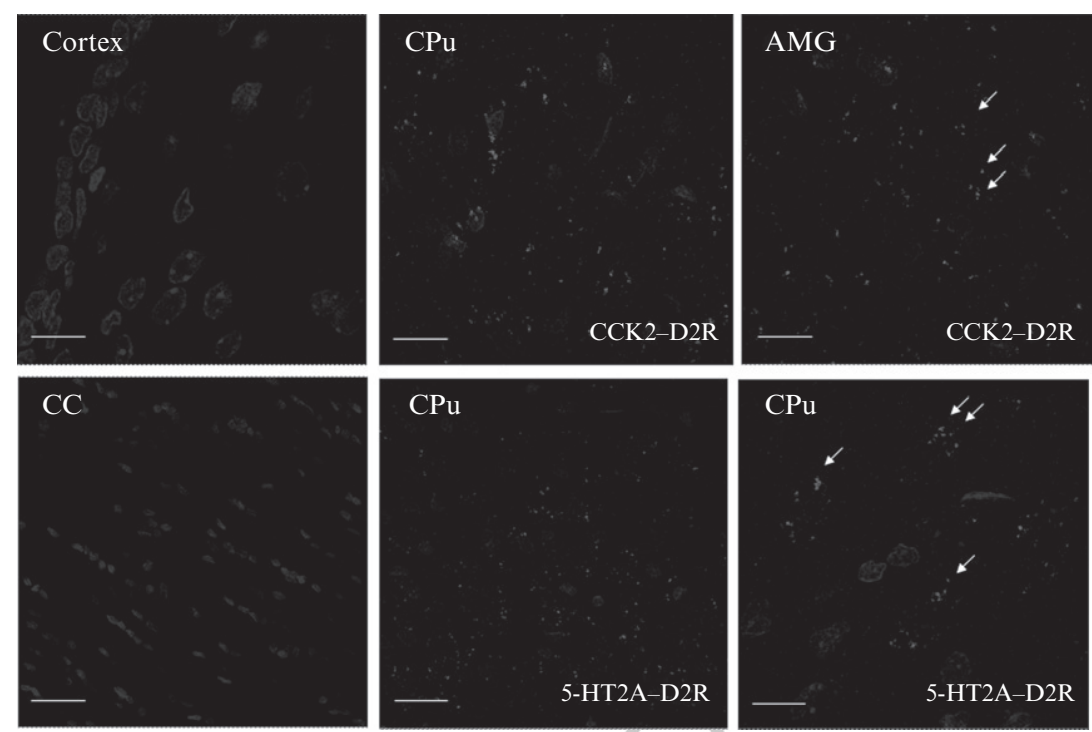

f0015 Figure 15.3 Detection of different GPCR-GPCR heteromers and GPCR-RTK heterocomplexes in dorsal rat hippocampal and striatal sections by in situ PLA. (A-upper panel) Constitutive FGFR1-5-HT1A heteroreceptor complexes are detected by in situ PLA (red clusters) in dorsal rat hippocampus (Ammon's horn 1 and 3 (CA1, CA3) but not, as an example, in the corpus callosum (cc). Scale bars, $20 \mu \mathrm{m}$. (A-lower panel) Constitutive FGFR1-M3R heteroreceptor complexes are detected by in situ PLA (red clusters) in dorsal rat hippocampus (granular layer of the dentate gyrus [DG]) but not in the cortex cerebri. Scale bars from the left to the right, 50,50, and $20 \mu \mathrm{m}$. (B-upper panel) Constitutive CCK2- $\mathrm{D}_{2} \mathrm{R}$ heteromers are detected by in situ PLA (red clusters) in striatal sections (caudate putamen: $\mathrm{CPu}$; amygdaloid cortex: $\mathrm{AMG}$ ) but not, for example, in the cortex cerebri. Scale bars, $20 \mu \mathrm{m}$. (B-upper panel) Constitutive $5-\mathrm{HT} 2 \mathrm{~A}-\mathrm{D}_{2} \mathrm{R}$ heteromers are detected by in situ PLA (red clusters) in striatal sections (caudate putamen: $\mathrm{CPu}$; amygdaloid cortex: AMG) but not, for example, in the corpus callosum (cc). Scale bars from the left to the right, 75, 50, and $20 \mu \mathrm{m}$. Nuclei appear as a blue color in all panels and the white arrows indicate the red cluster formation (PLA signal). (See Color Insert.)

changes in the total number of the two receptor populations. Of increasing importance will be to determine the agonist/antagonist regulation of these receptor heteromers in order to understand their potential roles as targets for drugs used in neuropsychopharmacology for treatment of psychiatric and neurological diseases. Analysis of human brain material with in situ PLA can also reveal if the relative abundance of specific receptor heteromers in discrete brain regions is altered in brain diseases (Fig. 15.3A and B). 
To protect the rights of the author(s) and publisher we inform you that this PDF is an uncorrected proof for internal business use only by the author(s), editor(s), reviewer(s), Elsevier and typesetter SPi. It is not allowed to publish this proof online or in print. This proof copy is the copyright property of the publisher and is confidential until formal publication.

B978-0-12-391862-8.00015-6, 00015

\section{ACKNOWLEDGMENTS}

This work has been supported by the Swedish Medical Research Council (04X-715) Torsten and Ragnar Söderberg Foundation (MN 65/08), Telethon TV3's La Marató Foundation 2008, and M.M. Wallenberg Foundation to K. F., and Karolinska Institutets Forskningsstiftelser 2010 and 2011 to D. O. B.- E. Also by grants SAF2008-01462 and Consolider-Ingenio CSD2008-00005 from Ministerio de Ciencia e Innovación to F. C. A. O. T. has not received any support for this work.

\section{REFERENCES}

Agnati, L. F., Fuxe, K., Zini, I., Lenzi, P., \& Hokfelt, T. (1980). Aspects on receptor regulation and isoreceptor identification. Medical Biology, 58, 182-187.

Allalou, A., \& Wahlby, C. (2009). BlobFinder, a tool for fluorescence microscopy image cytometry. Computer Methods and Programs in Biomedicine, 94, 58-65.

Borroto-Escuela, D. O., Garcia-Negredo, G., Garriga, P., Fuxe, K., \& Ciruela, F. (2010). The M(5) muscarinic acetylcholine receptor third intracellular loop regulates receptor function and oligomerization. Biochimica et Biophysica Acta, 1803, 813-825.

Borroto-Escuela, D. O., Romero-Fernandez, W., Mudo, G., Perez-Alea, M., Ciruela, F., Tarakanov, A. O., et al. (2012). Fibroblast growth factor receptor 1-5-hydroxytryptamine 1A heteroreceptor complexes and their enhancement of hippocampal plasticity. Biological Psychiatry, 71, 84-91.

Borroto-Escuela, D. O., Van Craenenbroeck, K., Romero-Fernandez, W., Guidolin, D., Woods, A. S., Rivera, A., et al. (2011). Dopamine D2 and D4 receptor heteromerization and its allosteric receptor-receptor interactions. Biochemical and Biophysical Research Communications, 404, 928-934.

Carpenter, A. E., Jones, T. R., Lamprecht, M. R., Clarke, C., Kang, I. H., Friman, O., et al. (2006). Cell Profiler: Image analysis software for identifying and quantifying cell phenotypes. Genome Biology, 7, R100.

Clausson, C. M., Allalou, A., Weibrecht, I., Mahmoudi, S., Farnebo, M., Landegren, U., et al. (2011). Increasing the dynamic range of in situ PLA. Nature Methods, 8, 892-893.

Ferre, S., Baler, R., Bouvier, M., Caron, M. G., Devi, L. A., Durroux, T., et al. (2009). Building a new conceptual framework for receptor heteromers. Nature Chemical Biology, 5, 131-134.

Fuxe, K., Agnati, L. F., Benfenati, F., Cimmino, M., Algeri, S., Hokfelt, T., et al. (1981). Modulation by cholecystokinins of $3 \mathrm{H}$-spiroperidol binding in rat striatum: Evidence for increased affinity and reduction in the number of binding sites. Acta Physiologica Scandinavica, 113, 567-569.

Fuxe, K., Borroto-Escuela, D. O., Marcellino, D., Romero-Fernandez, W., Frankowska, M., Guidolin, D., et al. (2012). GPCR heteromers and their allosteric receptor-receptor interactions. Current Medicinal Chemistry, 19, 356-363.

Leuchowius, K. J., Jarvius, M., Wickstrom, M., Rickardson, L., Landegren, U., Larsson, R., et al. (2010). High content screening for inhibitors of protein interactions and posttranslational modifications in primary cells by proximity ligation. Molecular \& Cellular Proteomics, 9, 178-183.

Leuchowius, K. J., Weibrecht, I., \& Soderberg, O. (2011). In situ proximity ligation assay for microscopy and flow cytometry. Current Protocols in Cytometry, 36 chapter 9, unit 9.

Limbird, L. E., Meyts, P. D., \& Lef kowitz, R. J. (1975). Beta-adrenergic receptors: Evidence for negative cooperativity. Biochemical and Biophysical Research Communications, 64, 1160-1168. 
To protect the rights of the author(s) and publisher we inform you that this PDF is an uncorrected proof for internal business use only by the author(s), editor(s), reviewer(s), Elsevier and typesetter SPi. It is not allowed to publish this proof online or in print. This proof copy is the copyright property of the publisher and is confidential until formal publication.

B978-0-12-391862-8.00015-6, 00015

Nilsson, I., Bahram, F., Li, X., Gualandi, L., Koch, S., Jarvius, M., et al. (2010). VEGF receptor 2/-3 heterodimers detected in situ by proximity ligation on angiogenic sprouts. The EMBO Journal, 29, 1377-1388.

Soderberg, O., Gullberg, M., Jarvius, M., Ridderstrale, K., Leuchowius, K. J., Jarvius, J., et al. (2006). Direct observation of individual endogenous protein complexes in situ by proximity ligation. Nature Methods, 3, 995-1000.

Soderberg, O., Leuchowius, K. J., Gullberg, M., Jarvius, M., Weibrecht, I., Larsson, L. G., et al. (2008). Characterizing proteins and their interactions in cells and tissues using the in situ proximity ligation assay. Methods, 45, 227-232.

Soderberg, O., Leuchowius, K. J., Kamali-Moghaddam, M., Jarvius, M., Gustafsdottir, S., Schallmeiner, E., et al. (2007). Proximity ligation: A specific and versatile tool for the proteomic era. Genetic Engineering, 28, 85-93.

Trifilieff, P., Rives, M. L., Urizar, E., Piskorowski, R. A., Vishwasrao, H. D., Castrillon, J., et al. (2011). Detection of antigen interactions ex vivo by proximity ligation assay: Endogenous dopamine D2-adenosine A2A receptor complexes in the striatum. BioTechniques, 51, 111-118. 
To protect the rights of the author(s) and publisher we inform you that this PDF is an uncorrected proof for internal business use only by the author(s), editor(s), reviewer(s), Elsevier and typesetter SPi. It is not allowed to publish this proof online or in print. This proof copy is the copyright property of the publisher and is confidential until formal publication.

B978-0-12-391862-8.00015-6, 00015

\section{Non-Print Items}

Keywords: Fibroblast growth factor receptor, Serotonin receptors, Neuronal plasticity, Receptor heterocomplex, Depression, Allosteric modulation 